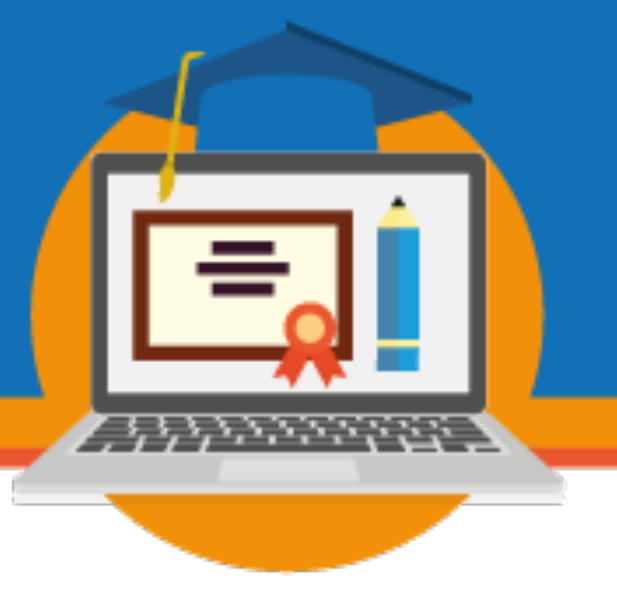

\title{
O AMBIENTE VIRTUAL DE APRENDIZAGEM MOODLE NA POIESE: POSSIBILIDADES DE CONVERGÊNCIA ENTRE PRESENCIALIDADE E VIRTUALIDADE
}

\author{
Janaina Angelina Teixeira \\ (SEDF/janaina.angelina@gmail.com) \\ Andréia Mello Lacé \\ (UnB/amlace@unb.br) \\ Lívia Veleda de Sousa e Melo \\ (UnB/liviamelo@unb.br) \\ Moises Silva de Sousa \\ (UnB/moises_silva98@hotmail.com) \\ Thiago dos Santos Brandão \\ (UnB/thiagob.unb@gmail.com)

\section{Denysberg Carvalho Alves de Resende \\ (UnB/awberg_denys@hotmail.com)}

Eixo 5: Educação híbrida: uma tendência na educação superior

Resumo: Este trabalho intenciona apresentar o ambiente virtual de aprendizagem Moodle na metodologia da Poiese, considerando a utilização de tecnologias educacionais na prática educativa e suas possibilidades de convergência entre as modalidades presencial e a distância. A Poiese é uma metodologia de aprendizagem construída por professoras da Faculdade de Educação da Universidade de Brasília, no âmbito do Programa Aprendizagem para o $3^{\circ}$ Milênio (A3M), na Universidade de Brasília, e envolveu estudantes dos cursos de Pedagogia, Artes Visuais, Licenciatura e Ciência da Computação e Engenharia de Redes de Comunicações. Os procedimentos metodológicos priorizaram grupos de discussões intempestivos que resultaram na implementação do projeto piloto (versão beta) do ambiente virtual de aprendizagem Moodle e depois a versão alpha, que se encontra em andamento. A Poiese apoia-se, entre outros, nos estudos de Paulo Freire (1989), Vygotsky (1991) e Dewey (2010). O desenvolvimento da metodologia, no ano de 2019, ressignificou a utilização da sala de aula, sugeriu maior envolvimento dos estudantes com o processo educativo e evidenciou potencial de convergência das modalidades presencial e a distância com o uso das TDICS. 


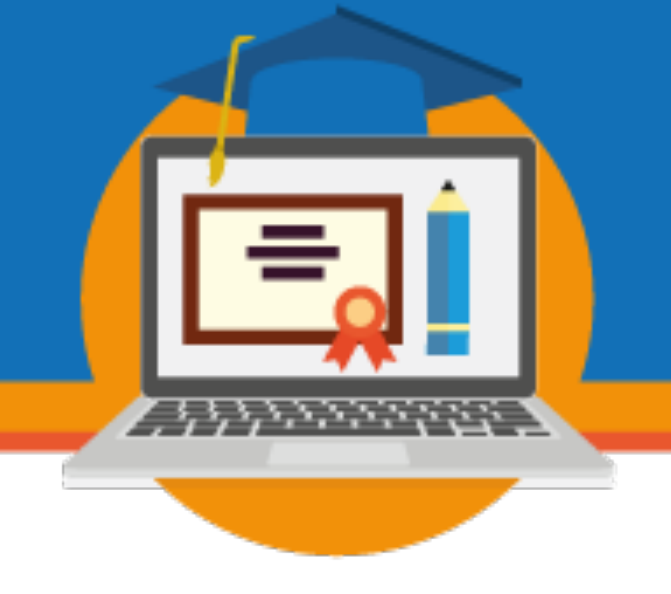

Palavras-chaves: Metodologia da Poiese. Ambiente virtual de Aprendizagem Moodle. Convergência entre presencialidade e virtualidade

\section{INTRODUÇÃO}

\subsection{A Poiese e algumas inquietações que antecederam o desenvolvimento da metodologia}

A metodologia da Poiese começou a ser desenvolvida na Faculdade de Educação, da Universidade de Brasília, por um grupo de professores e alunos de diferentes áreas do conhecimento (Pedagogia, Licenciatura em Ciência da Computação, Artes e Visuais e Engenharia de Redes de Comunicação). Mas, o que significa Poiese? Na etimologia, a palavra deriva do grego (poiesis) e está relacionada ao processo criativo e às experiências estéticas em diferentes campos da existência humana, inclusive o campo da educação. A partir disso, vale lembrar o artigo 52, da Lei de Diretrizes e Bases da Educação Nacional, em que uma das finalidades da universidade "é a formação para o domínio e cultivo do saber humano" (BRASIL, 1996). A questão de como materializar essa formação para o cultivo do saber humano, valorizando os processos criativos e às experiências estéticas, estão na base de nossas inquietações.

A concepção de sala de aula é uma questão que decorre da inquietação acima. Que espaço promissor é esse? Nossa percepção é conduzida por caminhos diversos daqueles que concebem a sala de aula, como sinônimo, de espaço para se ensinar lições, matérias e conteúdos que serão cobrados nas avaliações de aprendizagem. Ou seja, diverso das abordagens que concebem a sala de aula como espaço hierárquico e transitório. A sala de aula é sim espaço de lições e múltiplos registros, mas lições que transcendem o currículo, o conteúdo a ser ensinado e a ser aprendido.

Nos perguntávamos se a forma como enxergamos a sala de aula poderia dizer sobre a prática docente. Raul Pompéia (1888), sintetiza de forma representativa a sala de aula, na escola de regime de internato, mais conhecida como "o Ateneu": 


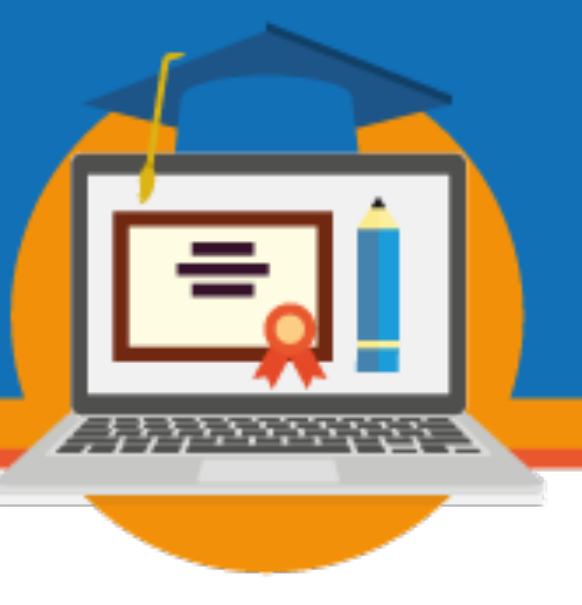

(...) Entretinha-me a espiar os companheiros, quando o professor pronunciou o meu nome. Fiquei tão pálido que Mânlio sorriu e perguntou-me, brando, se queria ir à pedra. Precisava examinar-me (...) $\mathrm{O}$ professor interrogou-me; não sei se respondi. Apossou-se-me do espírito um pavor estranho. Acovardou-me o terror supremo das exibições, imaginando em roda a ironia má de todos aqueles rostos desconhecidos. Amparei- me à tábua negra, para não cair; fugia-me o solo aos pés, com a noção do momento; envolveu-me a escuridão dos desmaios, vergonha eterna! (POMPÉIA, 1888, p. 6).

Embora guardemos distância temporal com o século XIX, a sala de aula nos espaços institucionais, seja de educação básica ou superior, ainda mantém semelhanças com os processos de ensino e aprendizagem do Brasil imperial. Algumas dessas constatações foram evidenciadas inclusive por meio da fala de estudantes da educação superior, sobretudo, das licenciaturas, desde o início dos anos 2000.

Tornar o aluno protagonista do seu processo de ensino/aprendizagem é um dos pressupostos do pensamento de Paulo Freire (1989), Vygotsky (1991), Dewey (2010) dentre outros. Docentes e discentes compartilhando a gestão da sala de aula, desde o planejamento até a avaliação, pressupõe ressignificação do sentido de docência e de sala de aula. Dewey (2010), em sua filosofia da arte como experiência desenvolve uma teoria densa que prima pela articulação entre o pensar e o fazer. Desse modo, a experiência estética não é sinônimo de fazer, de executar, pelo contrário, ela unifica ação, percepção e aprendizado (DEWEY, 2010). Pensar a sala de aula como espaço de múltiplas possibilidades para a efetivação da experiência estética, nos impulsiona a concretizar metodologias que primam pela aprendizagem significativa, problematizadora e prazerosa.

Em vista disso, a metodologia da Poiese foi colocada em prática por meio de um projeto apresentado ao Programa de Aprendizagem para o $3^{\circ}$ Milênio (A3M), da Universidade de Brasília, no Edital CEAD/DEG n.01/2018. O Projeto foi um dos contemplados no Edital para o seu desenvolvimento e implementação. O objetivo geral da Poiese foi criar a disciplina Organização da Educação Brasileira (OEB), em ambiente gamificado e com objetos de aprendizagem baseados em artes. 


\subsection{Por que OEB?}

O projeto iniciou sua aplicação na disciplina presencial Organização da Educação Brasileira (OEB), que é ofertada pelo Departamento de Planejamento e Administração (PAD) da Faculdade de Educação. A escolha dessa disciplina se justifica devido ao seu caráter obrigatório para todas as licenciaturas e vinculação das professoras que coordenam o projeto ao PAD. Além disso, OEB é uma disciplina em que os estudantes apresentam, historicamente, aversão, devido a seu caráter teórico legalista. Nas percepções discentes, os adjetivos "enfadonha" e "exaustiva" são recorrentes para a disciplina.

\subsection{AVA: A trilha de aprendizagem da Poiese}

O AVA foi desenvolvido para a aplicação da Poiese com base em uma trilha de aprendizagem que foi construída a partir das TDICS, com elementos presentes nos jogos, tais como o estabelecimento de regras (mesmo que flexíveis), espaço para o imponderável, para a sensação de incerteza e a compensação. Além dos objetos baseados em arte, que foram construídos articulando a corporificação dos avatares por meio de educadores importantes para a educação e as mais variadas linguagens (vídeos, memes, imagens, charges, poesias, matérias jornalísticas, etc). Assim, a trilha consiste no percurso formativo do estudante e promove, a partir dos Objetos de Aprendizagem (OA) e dos Objetos Orientadores de aprendizagens (OOA), experiências singulares na construção do conhecimento.

O OA baseado em Arte se evidencia por meio de cinco critérios, de acordo com Fernández et al., (2017): resultados singulares e não homogêneos, experiências estéticas, ou seja, permitem relações corporificadas e carregadas de sentido; favorece a imaginação e a criatividade; permite espaços de subjetivação na relação consigo e com o outro; e por fim, abre espaço para a diferença e o dissenso, para a dúvida e para a (re)construção do conhecimento. Os OAs baseados em arte podem ser construídos tanto por meio das TDICS, quanto por meio de objetos físicos tendo por base o papel ou qualquer outro artefato.

Para aplicação dos OAs baseados em arte é necessário um ambiente virtual que propicie essa aprendizagem singular. 


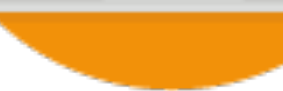

Nesse contexto, insere-se a gamificação que consiste em um conjunto de princípios aplicáveis a qualquer ramo de atividade, uma vez que aproveita a motivação, metas alcançáveis, o desejo das pessoas em realizar objetivos claros e bem definidos, feedback positivo, bem como se utiliza da competição para o atingimento de um comportamento pretendido (PIMENTA, 2014).

Para a Poiese, a gamificação pode ser considerada uma estratégia colaborativa que parte do princípio da experiência de aprendizagem do estudante. Ressalta-se que os jogos enquanto ferramentas educativas possuem um grande potencial, pois proporcionam ambientes de aprendizagem embasados na descoberta e na criatividade que pode gerar maior motivação do estudante (ZEA, et al., 2009).

O percurso de construção do AVA foi organizado em dois momentos, versão beta aplicada como um piloto no primeiro semestre de 2019 em seis turmas de OEB, e versão alfa, no segundo semestre de 2019, aplicada em 5 turmas de OEB da Faculdade de Educação.

Quanto ao primeiro momento de desenvolvimento do AVA, foram realizadas reuniões semanais com o grupo de pesquisadores. Nestes momentos, foram levantadas as possibilidades de uso das TDICS no ensino presencial com a customização do AVA e a construção dos objetos de aprendizagem baseados em arte. Depois de seis meses de trabalho tivemos a primeira versão da disciplina de OEB gamificada. Durante a aplicação da versão beta, o grupo reuniu-se quinzenalmente para avaliar os resultados da metodologia e algumas limitações foram levantadas: (a) a trilha foi desenvolvida em CSS fora do AVA, assim, ao clicar para acessar, o estudante era redirecionado para outra aba, dificultando a navegação; (b) os critérios da gamificação não ficaram claros para os estudantes o que fez com que esse elemento ficasse marginalizado na experiência dos usuários; (c) os avatares dos educadores não foram utilizados de forma a permitir a incorporação.

Em um segundo momento, a partir dos resultados com a versão beta, o grupo desenvolveu a versão alfa. Nesta versão, superou-seas limitações elencadas, o que possibilitou maior engajamento dos estudantes com a metodologia. Atualmente, o AVA conta com uma 


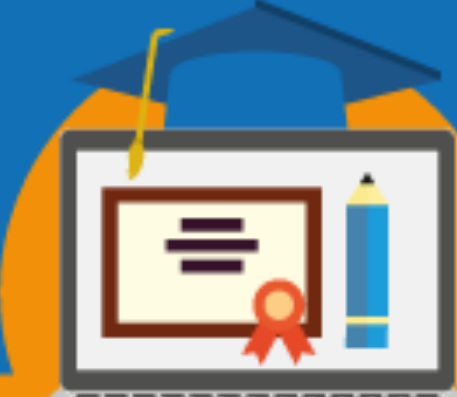

츨

trilha de aprendizagem desenvolvida por meio de um plugin customizado dentro da plataforma Moodle; a gamificação foi melhor contextualizada a partir da exposição das regras no início da disciplina e com o uso do plugin Block Game e os objetos de aprendizagem baseados em arte apresentam os avatares, bem como as possibilidades de incorporação. A Figura 1 representa a Trilha de Aprendizagem da Poiese.

Figura 1 - Trilha de aprendizagem
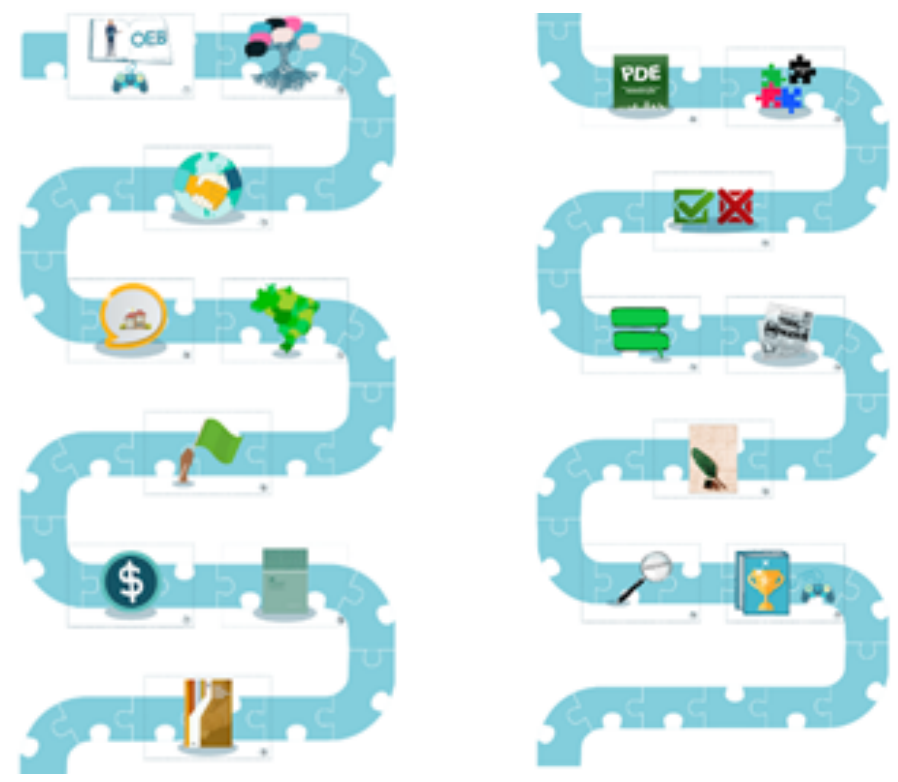

Fonte: Elaborado pelos autores, com base na pesquisa realizada no site, 2020.

A incorporação se concretizou por meio da utilização de avatares de diferentes educadores e educadoras brasileiros com notável relevância no cenário nacional.

Após longas discussões, foram selecionados e criados avatares para doze educadores (as): Anísio Teixeira, Carolina de Jesus, Cecília Meireles, Conceição Evaristo, Darcy Ribeiro, Dorina Nowill, Lourenço Filho, Florestan Fernandes, Milton Santos, Nise da Silveira, Paulo 


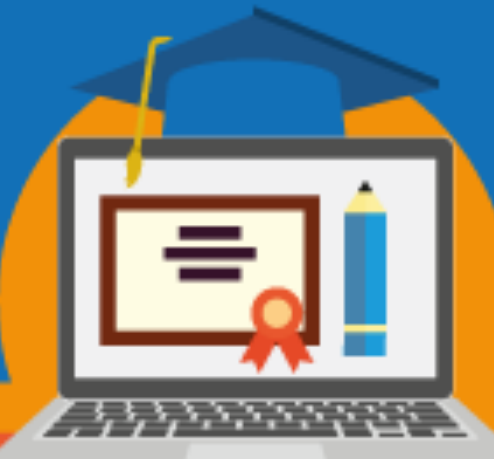

Freire e Antonieta de Barros (Figura 2). Importa considerar que todos os integrantes do projeto também tiveram seus avatares criados (Figura 3).

Figura 2: Avatares dos educadores e das educadoras brasileiras

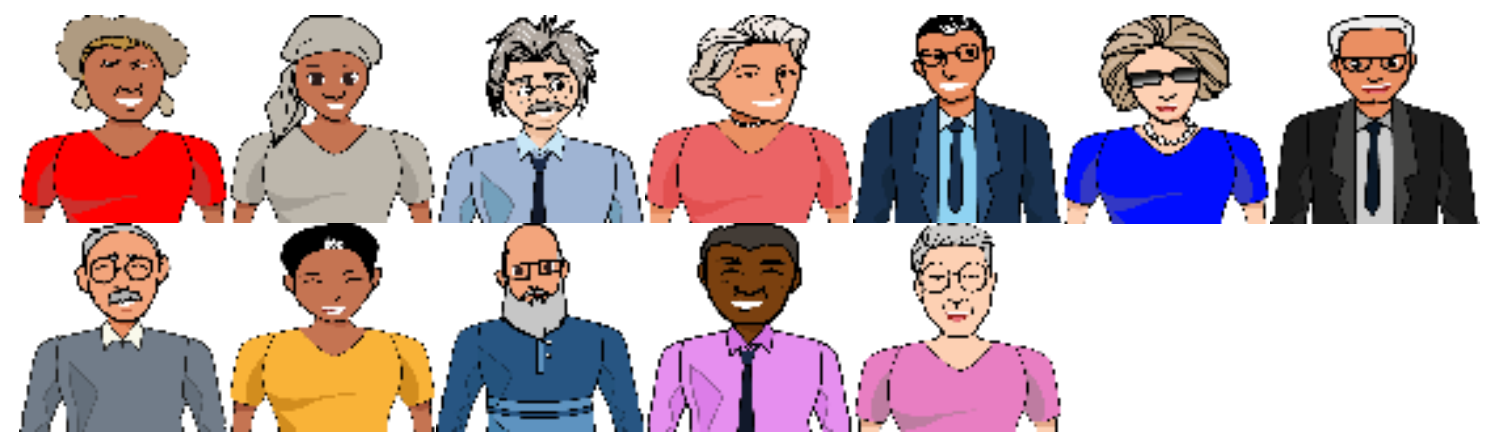

Fonte: Elaborado pelos autores, com base na pesquisa realizada no site, 2019.

Figura 3 - Avatares Equipe Poiese

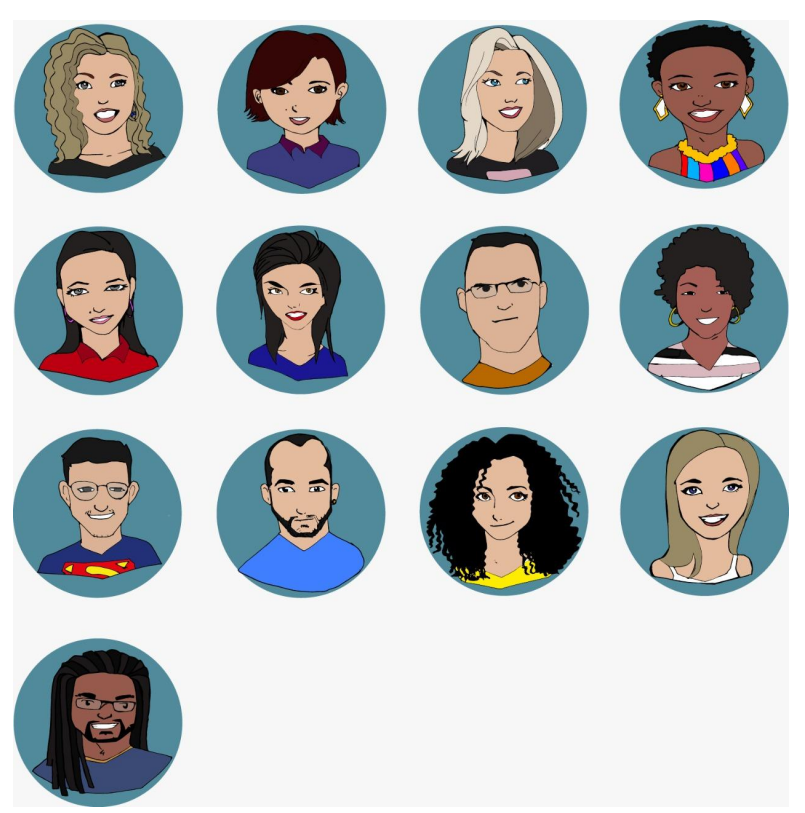

III SEMINÁRIO DE EDUCAÇÃO A DISTÂNCIA

Diálogos sobre EaD e uso das TDIC na educação: regulamentação em tempos recentes

3 a 6 de novembro de 2020 - Brasília/DF - Online 


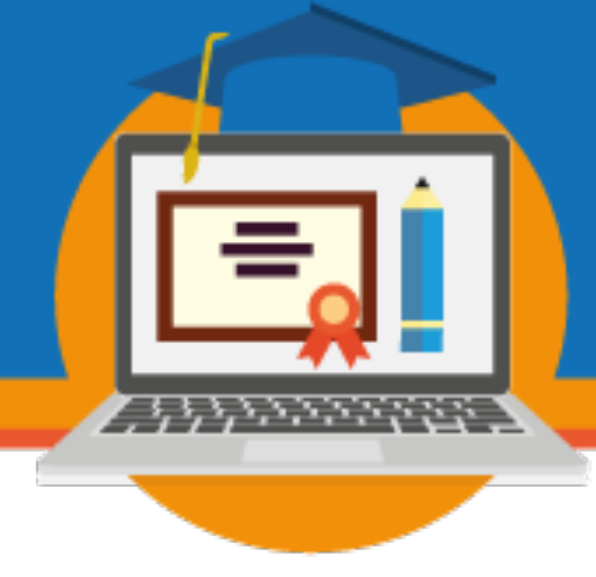

Fonte: Elaborado pelos autores, com base na pesquisa realizada no site, 2019.

A gamificação por meio do plugin Block Game, ganhou o nome de "Minha trilha em OEB" e pode ser conferida na Figura 4.

Figura 4: Bloco "Minha Trilha em OEB"

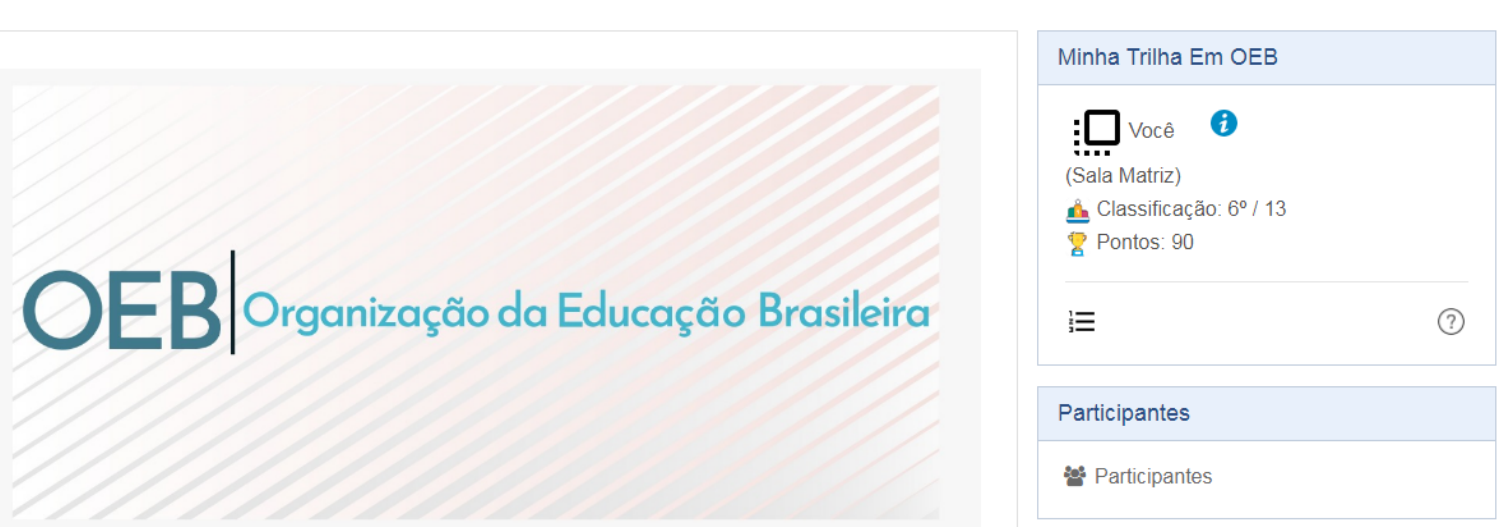

Fonte: Elaborado pelos autores, com base na pesquisa realizada no site, 2019.

A partir de uma trilha de aprendizagem, na qual os estudantes podem acompanhar seu processo de aprendizagem de forma contextualizada e interativa, a Poiese busca proporcionar a convergência das modalidades presencial e a distância por meio do uso das TDICS, articuladas às aulas presenciais. Essa articulação parte do pressuposto de "flexibilização" dos espaços de ensino e aprendizagem, em que emergem novas possibilidades de experimentação do tempo, onde uma sala de aula está em todo lugar e a qualquer tempo no ciberespaço (MILL, 2014).

\subsection{Os primeiros resultados}

A Poiese começou a ser pensada e implementada desde 2014, nos cursos de licenciatura da Universidade de Brasília, de forma experimental. No decorrer do segundo semestre de 2018 e dos semestres de 2019, a metodologia foi aperfeiçoada por professores e estudantes. Durante 


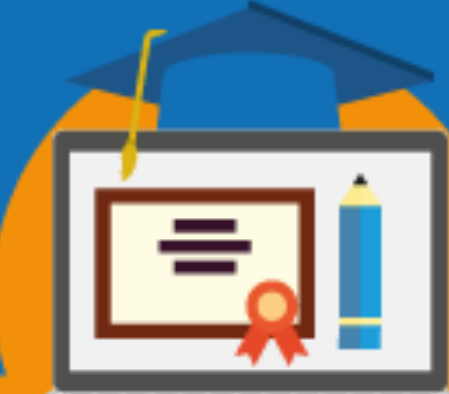

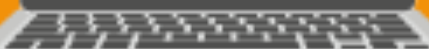

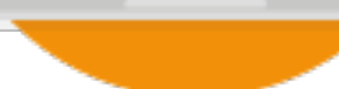

este ano, a Poiese foi aplicada em seis turmas da disciplina de Organização da Educação Brasileira (OEB). A experiência do planejamento, da execução e da avaliação possibilitou extrair um conjunto de temas para reflexão e problematização. Destacaremos três deles.

O primeiro diz respeito ao potencial do uso das TDICs na educação presencial atrelado ao planejamento pedagógico e, consequentemente, à concepção de educação, docência/discência e sala de aula. Concordamos com Kenski, 1998; Masetto, 2000, quando estas evidenciam o uso das tecnologias como meio para o alcance de resultados pedagógicos críticos e criativos. Desse modo, a tecnologia permite transcender usos lineares e finalísticos e tende a se constituir como importante aliada para o alcance dos objetivos de aprendizagem. $\mathrm{Na}$ Poiese, o ambiente virtual de aprendizagem em formato de trilha, ao simular um jogo virtual, se apresentou como um espaço para abrigar múltiplos recursos e, simultaneamente, para abrigar múltiplas produções e (re)elaborações do conhecimento. Seja em forma de vídeos, memes, paródias, narrativas temáticas, pesquisa de campo, dentre outros. Conforme exemplos abaixo:

Imagens 1, 2, 3, e 4 - Produções dos alunos na disciplina OEB/UnB/2019
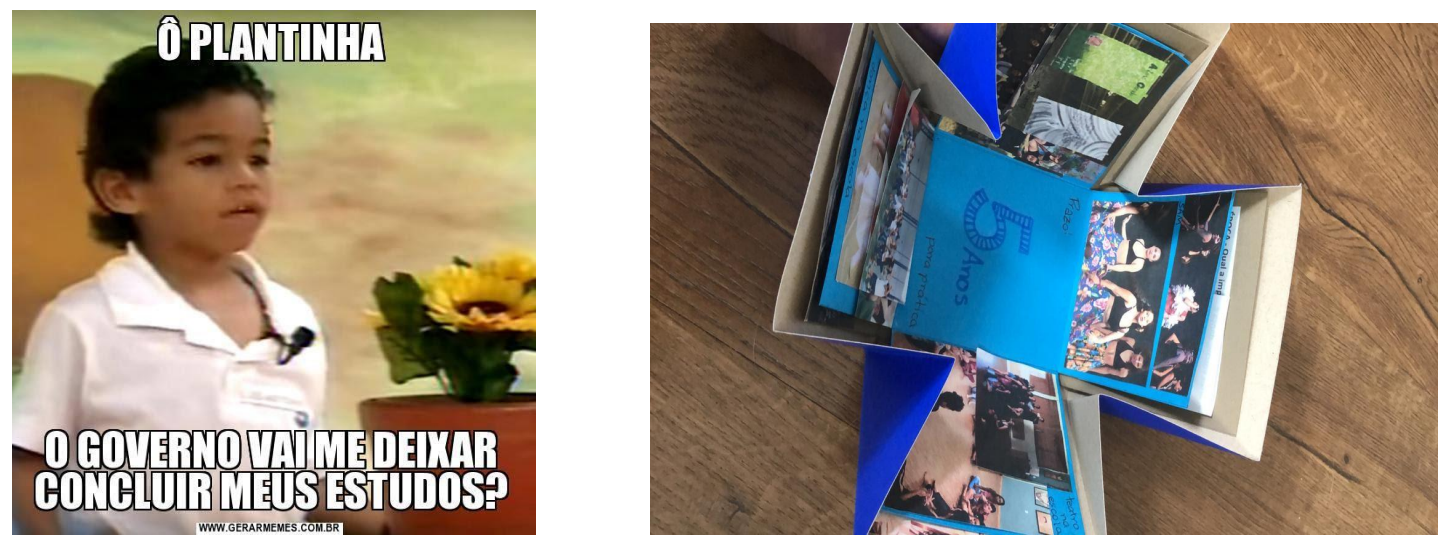


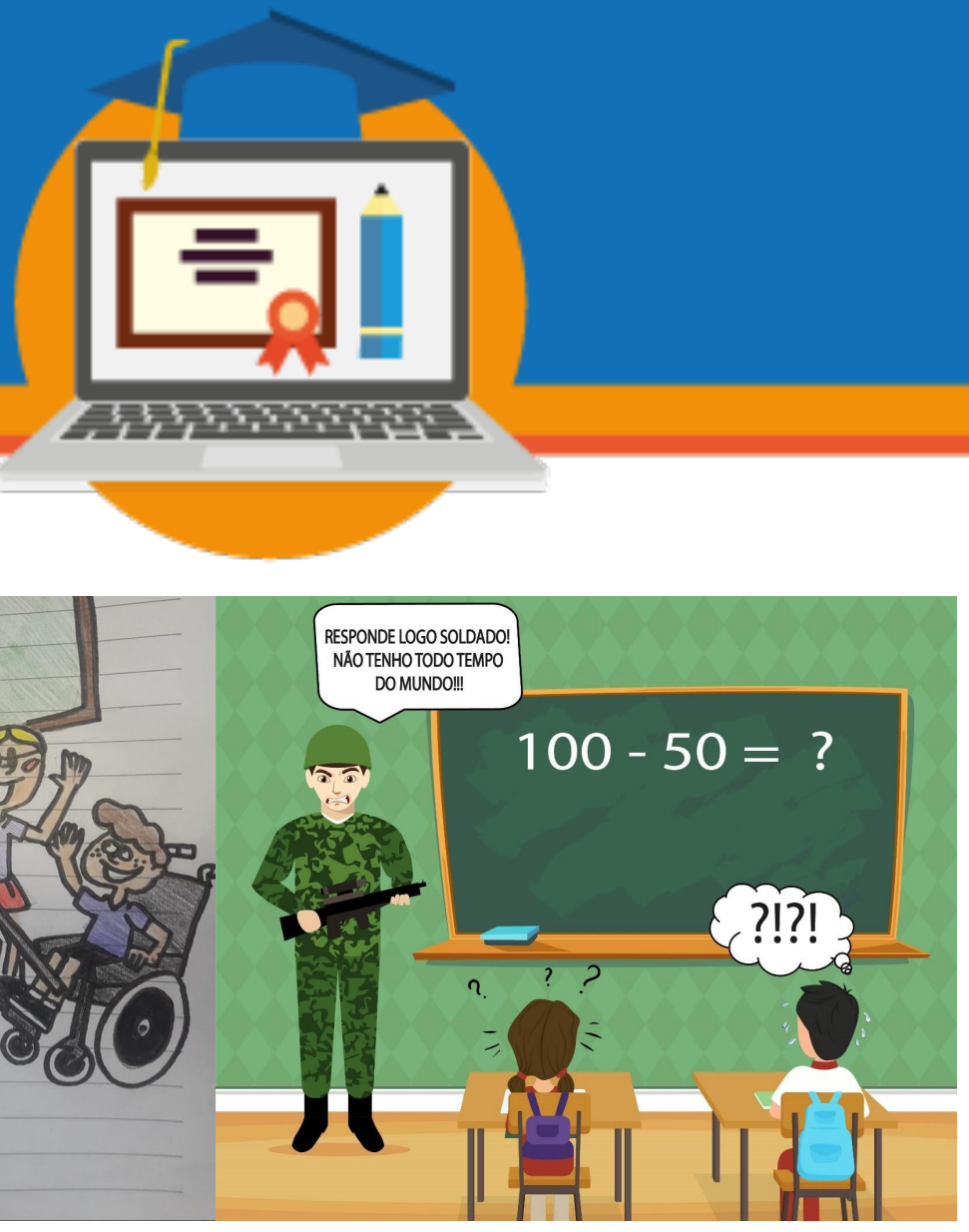

Nesse aspecto, importa considerar que o desenvolvimento da disciplina OEB no ciberespaço; bem como o uso dos avatares para despertar curiosidade, ampliação de repertórios e o fomento de possibilidades contou com o apoio institucional. Aqui entra a segunda reflexão. O Programa Aprendizagem para o $3^{\circ}$ Milênio é uma ação institucional com o intuito de identificar, valorizar e promover ações educacionais inovadoras na UnB. O Programa tem como meta a disponibilização de um Portfólio com possibilidades de inovação educacional. Por meio do Programa A3M, a UnB executou dois editais de fomento a projetos desenvolvidos por professores da instituição, totalizando 56 propostas em andamento, entre as quais a Poiese. Esse apoio institucional foi de suma relevância para o andamento do projeto, possibilitando a participação de alunos de diferentes cursos na construção e a divulgação para toda a comunidade acadêmica.

O último tema se refere ao que Mill (ano) chamou de flexibilização da sala de aula. A experiência na Poiese trouxe evidências de que é possível ressignificar tempo e espaço de ensino/aprendizagem, inclusive, na educação presencial. A metodologia pode apresentar forte tendência para colaborar com o uso do ensino híbrido na UnB e para trazer elementos que conduzam à formação docente e a um novo desenho de cursos oferecidos na modalidade $\mathrm{EaD}$, por meio do programa Universidade Aberta do Brasil.

\section{SEMINÁRIO DE EDUCAÇÃO A DISTÂNCIA}

Diálogos sobre EaD e uso das TDIC na educação: regulamentação em tempos recentes 3 a 6 de novembro de 2020 - Brasília/DF - Online 


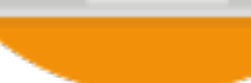

Além disso, dos temas destacados acima, podemos assinalar que os resultados obtidos com os estudantes, bem como a produção do conhecimento, evidenciaram respostas singulares e criativas com as temáticas tratadas na disciplina. Alguns objetos de aprendizagem foram mais exitosos do que outros. Dentre eles: a produção criativa para tratar do direito à educação, o(a) repórter por um dia para discutir a função social da escola, o Júri Simulado utilizado para problematizar a Lei n. 13.415/2017, pelo qual se reformou o ensino médio no Brasil, e a narrativa temática com o objetivo de sistematizar um dos temas tratados na disciplina.

Outro aspecto a ser pontuado, se refere à construção paulatina da aprendizagem em rede e compartilhada, pois a sua aplicação exige quebra de paradigmas com práticas competitivas ainda predominantes na educação básica e superior. Nessas experiências estéticas/criativas, a dialogicidade e amorosidade (FREIRE, 1989) pelas pessoas e pelo ato de educar foram fundantes.

\section{Considerações Finais}

A aplicação da metodologia no primeiro semestre de 2019, em seu piloto, possibilitou, a partir dos retornos dos estudantes e das reflexões da equipe do projeto, aperfeiçoamentos para a aplicação no segundo semestre de 2019. Um dos mais importantes pontos de destaque foi avançar na incorporação dos educadores nas atividades propostas durante a trilha de aprendizagem, uma vez que a incorporação é uma das características dos $\mathrm{OAB}$, e foi um aspecto pouco trabalhado nas estratégias de aprendizagem e recursos produzidos na versão beta. Nas constantes avaliações do desenvolvimento do projeto, optamos por repensar essa estratégia de incorporação no intuito de propiciar maior identificação entre os educadores e os temas abordados.

Por outro lado, demonstrou-se exitosa evidenciando maior envolvimento dos estudantes, na construção de aprendizagens em rede e na produção singular do conhecimento na disciplina Organização da Educação Brasileira (OEB). A sala de aula se configurou como o espaço de 
encontro, de diálogo, de mediação e de constante recriação do sentido atribuído ao ensino e à aprendizagem.

Ressalta-se ainda a importância da formação da equipe do projeto e o envolvimento de todos, desde a concepção até a resolução de questões mais cotidianas.

Novas questões se apresentam na busca contínua pelo aperfeiçoamento da metodologia, tais como a aplicação de questionário aos estudantes e a realização de grupos de discussões para analisar com maior objetividade o engajamento dos estudantes. Observou-se ainda que a gestão do ambiente virtual de aprendizagem ficou fragilizada haja vista que o professor não possui autonomia de gestão no AVA hospedado na Universidade e depende de vários setores para configurar e disponibilizar os blocos da trilha virtual. Porém, esse aspecto não afetou a metodologia da Poiese em si, uma vez que não impactou no envolvimento dos estudantes. Por outro lado, a autonomia de gestão do AVA, por parte do professor, é estruturante para que os elementos da gamificação possam ser utilizados de forma mais eficaz.

Por fim, as tecnologias digitais de informação e comunicação podem ser importantes aliadas no processo formativo presencial e a distância e devem responder à concepção de educação, de ensino/aprendizagem, de gestão de aprendizagem no ciberespaço e ao planejamento pedagógico.

\section{Agradecimentos}

Em especial ao professor Leonardo Lazarte (UnB) que, gentilmente, disponibilizou o Moodle da GigaCandanga para a execução do Projeto. A GigaCandanga foi parceira essencial para a concretização da ideia; e ao professor José Wilson da Costa (SEEDF) pelo apoio tanto no planejamento, quanto no desenvolvimento do projeto. O professor José Wilson foi o responsável pelo desenvolvimento do plugin Block Game e da trilha virtual de aprendizagem no formato grid. Ao Centro de Educação a Distância da UnB e ao Decanato de Graduação pela preocupação com um dos pilares mais importantes da Universidade: o ensino. 


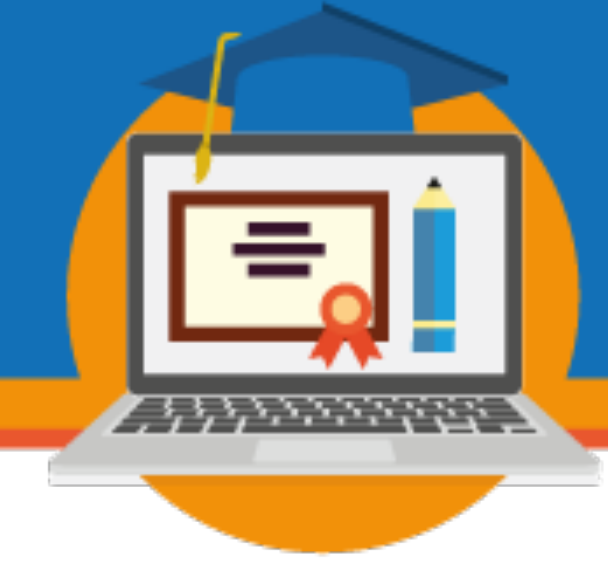

\section{REFERÊNCIAS}

BRASIL. Lei de Diretrizes e Bases da Educação Nacional [1996]. Disponível em http://www.planalto.gov.br/ccivil_03/leis/19394.htm. Acesso em:16 nov. 2019.

DEWEY, John. Arte como experiência. São Paulo: Martins Fontes, 2010.

FERNÁNDEZ, Tatiana et al. Os objetos de aprendizagem nos processos de formação docente na educação em artes visuais. Curitiba: Blanche, 2017.

FREIRE, Paulo. Educação como prática de liberdade. São Paulo: Paz e Terra, 1989.

FREIRE, Paulo. Pedagogia da autonomia. São Paulo: Paz e Terra, 1996.

KENSKI, V. Novas tecnologias: o redimensionamento do espaço e do tempo e os impactos no trabalho docente. Revista Brasileira de Educação, n. 8, Brasília, p. 58-71, maio/ago. 1998.

MASETTO, M. T. Mediação pedagógica e o uso da tecnologia. In: MORAM, J. M.; MASETTO, M. T.; BEHRENS, M. A. Novas tecnologias e mediação pedagógica. Campinas: Papirus, 2000.

MILL, Daniel. Flexibilidade educacional na cibercultura: analisando espaços, tempos e currículo em produções científicas da área educacional. RIED. Revista Iberoamericana de Educación a Distancia, v. 17, n. 2, p. 97-126, 2014.

PIMENTA, Fabrícia. Faleiros. Gamificação na Aprendizagem Colaborativa Online Não é um jogo, acredite! Não são só pontos, recompensas e desafios...Relatório de pesquisa de Pós Doutorado. Faculdade de Educação da UnB, 2014.

POMPÉIA, Raul. O ateneu. São Paulo: Editora Ática, 1996. VYGOTSKI, Lev. Semyonovich. A formação social da mente. São Paulo: Martins Fontes, 1991.

WOSNIAK, Fábio et al. Arte como experiência: ensino/aprendizagem em Artes Visuais. Disponível em: http://seer.ufrgs.br/index.php/gearte/article/view/62933/38582. Acesso: 31 maio 2017.

ZEA, Natalia Padilla et al. Diseño de Videojuegos Colaborativos y Educativos Centrado en la Jugabilidad. IEEE-RITA, v. 4, n. 3, p. 191-198, 2009. 


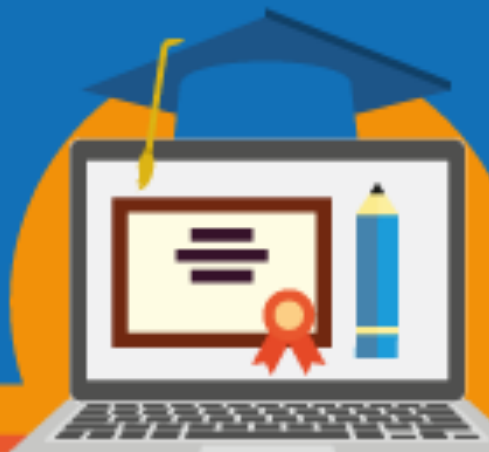

III SEMINÁRIO DE EDUCAÇÃO A DISTÂNCIA

Diálogos sobre EaD e uso das TDIC na educação: regulamentação em tempos recentes 3 a 6 de novembro de 2020 - Brasília/DF - Online 